\title{
A Combined Strategy of Sedation Guided by Bispectral Index, ICP Monitoring and Mild Hypothermia to Deal with Refractory Intracranial Hypertension: A Case Report
}

Cao C, Gao $H^{*}$, Wu W, Wang HX, Yang L, Yan KX, Huang LP and Lu YP

Department of Neurosurgery, The Affiliated Jiangyin Hospital, School of Medicine, Southeast University, Jiangyin City, Jiangsu Province, P.R China

\begin{abstract}
Traumatic brain injury (TBI) has become a worldwide public health problem due to its high mortality and morbidity. Refractory intracranial hypertension $(\mathrm{ICH})$, secondary to $\mathrm{TBI}$, always results in poor prognosis and sometimes even death. Sedation, intracranial pressure (ICP) monitoring and mild hypothermia have been proven effective in monitoring and controlling ICH after TBI. Here we present a case of 55-year-old male suffering from acute TBI.
\end{abstract}

Keywords: Intracranial hypertension; Traumatic brain injury

\section{Introduction}

Bispectral index (BIS) is widely used to monitor the depth of anesthesia during surgery [1,2]. BIS is also used as a tool to assess the sedation depth of TBI and guide the use of sedatives in some studies [3-5]. In this study, we presented a patient with refractory ICH due to TBI, and treated him with a combined strategy of sedation guided by BIS monitoring, ICP monitoring and mild hypothermia, a strategy producing a favorable outcome.

\section{Case Presentation}

A 55-year-old male was admitted to our department suffering from acute TBI due to a fall accident from a high place 2 hour previously. He was unconsciousness with GCS 11 (E3V3M5), and his pupillary light reactions showed equal and reactive pupils on both sides. The neurological examination was negative. A computed tomography (CT) scan showed cerebral contusion of his bilateral temporal lobes and left occipital lobe. After admission, he was treated with the firsttier treatments to reduce ICP: reverse trendelenburg, oxygen therapy, measures to maintain $\mathrm{PaCO}_{2} 4.5-5.0 \mathrm{kPa}$ and so on. A second CT scan was taken 6 hours later, which showed an aggravation of his left temporal contusion, accompanied by increased confusion. More aggressive treatments were applied, including an ICP probe (Codman, Johnson and Johnson, USA) being implanted into the cerebral cortex via the right frontal. His ICP was as high as $23 \mathrm{mmHg}(1 \mathrm{mmHg}=0.133$ $\mathrm{kPa}$ ). Sedation induced by dexmedetomidine (induction: $0.4 \mathrm{ug} / \mathrm{kg}$; maintenance: $0.08-1.0 \mathrm{ug} / \mathrm{kg} / \mathrm{hour}$ ), midazolam (induction: $0.1 \mathrm{mg} / \mathrm{kg}$; maintenance: $0.02-0.2 \mathrm{mg} / \mathrm{kg} / \mathrm{hour}$ ), and propofol (induction: $2 \mathrm{mg} /$ $\mathrm{kg}$; maintenance: $0.4-4.0 \mathrm{mg} / \mathrm{kg} / \mathrm{hour}$ ) was also used to reduce ICP, and we applied BIS monitoring to guide the sedation level (BIS 4060 ). The BIS was measured with a BIS monitor continuously (Aspect Medical System, Newton, MA, USA). A BIS-Quatro electrode was placed on the right forehead. During the monitoring, the indicators such as signal quality index (SQI) and electromyography activity (EMG activity) were observed. We maintained SQI $>80 \%$ and EMG $<50 \mathrm{~dB}$ in order to achieve reliable BIS values. In the next two days the patient's ICP was lower than $25 \mathrm{mmHg}$. However, his ICP increased to more than $30 \mathrm{mmHg}$ for more than 30 minutes. Another CT scan showed aggressive cerebral edema, and the basal cistern was narrow. Decompressive surgery may be one of the best options to rescue ICH, but his authorizer refused the option of removing the mass to relieve $\mathrm{ICH}$. A further application of mild hypothermia (maintaining a core temperature of $34 \sim 35^{\circ} \mathrm{C}$ ) was conducted to reduce refractory ICH.
Mild hypothermia was induced by an ice blanket machine (HGT-200, HOKAI, Zhuhai, China). Our goal was trying to keep the ICP value less than $25 \mathrm{mmHg}$. BIS monitoring interval was still maintained between 40 and 60 to guide the depth of sedation. ICP monitoring and intermittent CT scans were used to assess the cerebral edema and the shape of the basal cistern. This aggressive therapy strategy combined of sedation guided by BIS, ICP monitoring and mild hypothermia lasted 2 weeks. On his $40^{\text {th }}$ day of hospitalization, he discharged with a GOS of $4 / 5$, and his follow up showed total recovery.

\section{Discussion}

Refractory ICH is the most common issue leading to an unfavorable outcome after TBI. In order to control the refractory ICH, several measures can be applied, including sedation, ICP monitoring and mild hypothermia [1]. Although sedation is necessary for severe TBI patients, we were unable to come to an agreement on how to monitor the sedation level of TBI.

The Richmond Agitation-Sedation Scale (RASS) and SedationAgitation Scale (SAS) are most often used to monitor the sedation level after TBI [2]. But neither of them was totally suitable for TBI because of its subjectivity. In addition, evaluating accurately is difficult because of unconsciousness after TBI.

So, it's significant to find an objective measure to monitor and evaluate the sedation level after TBI. And it's also meaningful to achieve an ideal sedation level effectively by this means.

Electroencephalography (EEG) can be used to monitor the sedation level, and it had been used in the study of barbiturate therapy, which can reduce refractory ICH after TBI [1]. However,

*Corresponding author: Gao Heng, PhD, Department of Neurosurgery, The Affiliated Jiangyin Hospital, School of Medicine, Southeast University, 163 Shoushan Road, Jiangyin City, Jiangsu Province, P.R China, Tel: 86258379 2671; Email: dr.gaoheng@qq.com

Received December 29, 2017; Accepted January 08, 2018; Published January 15 2018

Citation: Cao C, Gao H, Wu W, Wang HX, Yang L, et al. (2018) A Combined Strategy of Sedation Guided by Bispectral Index, ICP Monitoring and Mild Hypothermia to Deal with Refractory Intracranial Hypertension: A Case Report. Brain Disord Ther 7: 242. doi: 10.4172/2168-975X.1000242

Copyright: () 2018 Cao C, et al. This is an open-access article distributed under the terms of the Creative Commons Attribution License, which permits unrestricted use, distribution, and reproduction in any medium, provided the original author and source are credited. 


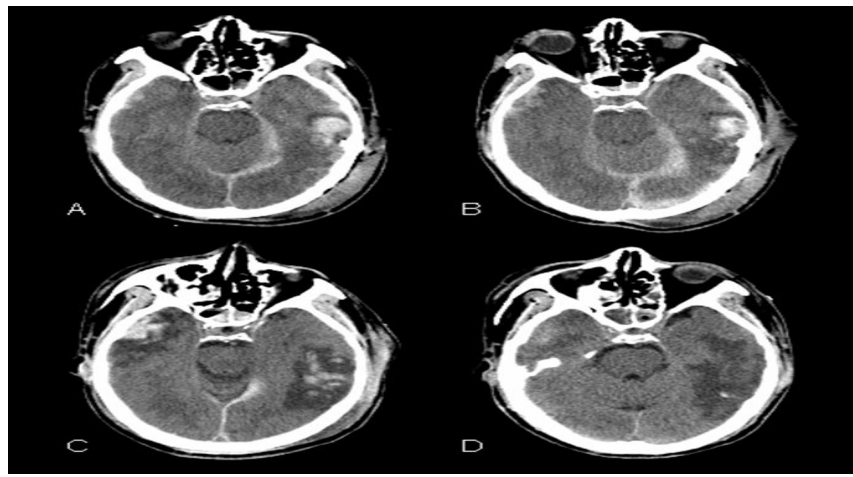

Figure 1: A. CT scan at admission showed cerebral contusion of patient's bilateral temporal lobes and left occipital lobe; B. $6 \mathrm{~h}$ after admission, CT scan revealed an aggravation of his left temporal contusion; C. CT scan showed aggressive cerebral edema, and the basal cistern was narrow on the $3^{\text {rd }}$ day after admission; D. 2 weeks later a CT scan showed cerebral edema subsiding, and the shape of the basal cistern restoring.

long-term EEG monitoring has not been widely used because it is so specialized. Quantified EEG monitoring is more accessible than EEG. BIS is a quantified parameter derived from EEG, and it provides a dimensionless number that varies from 0 to 100 : 90-100 means a normal state; the lower the number below 90, the deeper the level of sedation; and 0 represents total suppression of cortical electrical activity. The FDA recommends the use of BIS to monitor the depth of anesthesia during surgery [3]. In recent years, the application of BIS has been more extensive, such as monitoring patients with epilepsy [4], and predicting prognosis of TBI [5,6-8]. In addition, BIS is often used to monitor the sedation level of non-neurological patients [9-11]. Moreover, BIS replaced EEG in several studies on barbiturate coma therapy. And during barbiturate therapy the monitored BIS ranged from 5 to 15 [9-11].

In this case, we combined BIS monitoring, ICP monitoring, longterm mild hypothermia, hypertonic therapy and other means to control refractory ICH successfully, and the patient fully recovered. Setting a target BIS interval and using BIS to monitor the depth of sedation are helpful measures in reducing the incidence of inappropriate sedation, particularly over-sedation. Sedative drugs could reduce agitation and ICP but may also cause adverse reactions such as unstable blood pressure, in which case patients suffering from TBI become vulnerable to a low cerebral perfusion. And this may result in secondary cerebral ischemia, and lead to poor prognosis [1]. Besides, the overuse of a sedative can also lead to severe sedative-related adverse reactions, such as propofol infusion syndrome [12]. In a word, attaining a suitable sedation level induced by appropriate sedatives with guiding by BIS monitoring is particularly important in the management of refractory ICH after TBI.

There have been few studies of BIS monitoring as a measure to guide sedation levels in TBI patients $[2,13]$. One possible reason may be that the algorithm of BIS is derived from the analysis of a large number of EEGs of volunteers and patients under sedation and general anesthesia with different anesthetics, and the algorithm is complex and susceptible to many confounding factors [3]. Although the way that homolateral cerebral ischemia brain injury may influence BIS values has been described in the literature $[11,12,14-17]$ there is no guideline recommendation on how to monitor depth of sedation after TBI, making it indispensable to probe into the appropriate method to monitor sedation levels. BIS monitoring is noninvasive and quantified.
It's not complicated, and is easy to conduct [18]. When we monitor sedation levels by BIS, we should avoid the interference factor of BIS as much as possible. For example, we should apply it to patients with non-bilateral supratentorial cerebral contusion, as well as those without massive cerebral injury. The BIS electrode should be placed on the forehead of the normal side that indicates no obvious cerebral contusion $[11,12,14]$.

\section{Conclusion}

In our experience, monitoring the BIS by confirming the SQI and EMG appropriately is especially important (Figures 1A-1D). More research studies are needed to validate the applicability of BIS monitoring for different types of TBI and to set appropriate BIS cutoffs for different sedation levels prior to BIS monitoring to provide improved management of TBI patients [19,20].

\section{Acknowledgments}

Work was supported by the Wuxi Foundation for Development of Science and Technology, China (CSE31N1521).

\section{References}

1. Carney N, Totten AM, O'Reilly C, Ullman JS, Hawryluk GW, et al. (2017) Guidelines for the management of severe traumatic brain injury, (14th edn). Neurosurgery 80: 6-15.

2. Deogaonkar A, Gupta R, DeGeorgia M, Sabharwal V, Gopakumaran B, et al (2004) Bispectral index monitoring correlates with sedation scales in braininjured patients. Crit Care Med 32: 2403-2406

3. Duarte LT, Saraiva RA (2009) When the bispectral index (bis) can give false results. Rev Bras Anestesiol 59: 99-109.

4. Dahaba AA, Liu DW, Metzler H (2010) Bispectral index (BIS) monitoring of acute encephalitis with refractory, repetitive partial seizures (AERRPS). Minerva Anestesiol 76: 298-301.

5. Dong L, Chen L, Shi T, Wei M, Zhang HZ, et al. (2016) Combined monitoring of intracranial pressure and bispectral index in patients with severe craniocerebral trauma post-operatively. Clin Neurol Neurosurg 148: 42-44.

6. Haug E, Miner J, Dannehy M, Seigel T, Biros M (2004) Bispectral electroencephalographic analysis of head-injured patients in the emergency department. Acad Emerg Med 11: 349-352.

7. Ebtehaj M, Yaqubi S, Seddighi AS, Seddighi A, Yazdi Z (2012) Correlation between BIS and GCS in patients suffering from head injury. Ir J Med Sci 181 $77-80$.

8. Schmitt S, Dichter MA (2015) Electrophysiologic recordings in traumatic brain injury. Handb Clin Neurol 127: 319-339.

9. An HS, Cho BM, Kang JH, Kim MK, Oh SM, et al.(2010) Efficacy of low dose barbiturate coma therapy for the patients with intractable intracranial hypertension using the bispectral index monitoring. J Korean Neurosurg Soc 47: 252-257.

10. Riker RR, Fraser GL, Wilkins ML (2003) Comparing the bispectral index and suppression ratio with burst suppression of the electroencephalogram during pentobarbital infusions in adult intensive care patients. Pharmacotherapy 23 1087-1093.

11. Prins SA, de Hoog M, Blok JH, Tibboel D, Visser GH (2007) Continuous noninvasive monitoring of barbiturate coma in critically ill children using the Bispectral index monitor. Crit Care 11: R108.

12. Fudickar A, Jacobsen JH, Weiler N (2009) Bilateral measurement of bispectra index and mid-latency auditory evoked potentials in patients with unilateral brain lesions. J Crit Care 24: 545-550.

13. Jung JY, Cho CB, Min BM (2013) Bispectral index monitoring correlates with the level of consciousness in brain injured patients. Korean J Anesthesiol 64 246-250.

14. Cottenceau V, Masson F, Soulard A, Petit L, Guehl D, et al. (2012) Asymmetry of Bispectral Index (BIS) in severe brain-injured patients treated by barbiturates with unilateral or diffuse brain injury. Ann Fr Anesth Reanim 31: e275-281. 
Citation: Cao C, Gao H, Wu W, Wang HX, Yang L, et al. (2018) A Combined Strategy of Sedation Guided by Bispectral Index, ICP Monitoring and Mild Hypothermia to Deal with Refractory Intracranial Hypertension: A Case Report. Brain Disord Ther 7: 242. doi: 10.4172/2168-975X.1000242

Page 3 of 3

15. Heller H, Hatami R, Mullin P, Sciacca RR, Khandji AG, et al.(2005) Bilateral bispectral index monitoring during suppression of unilateral hemispheric function. Anesth Analg 101: 235-241.

16. Lee EH, Choi IC, Song JG, Jeong YB, Hahm KD, et al. (2009) Different bispectral index values from both sides of the forehead in unilateral carotid artery stenosis. Acta Anaesthesiol Scand 53: 134-136.

17. Kodaka M, Nishikawa Y, Suzuki T, Asano K, Maeyama A, et al. (2009) Does bilateral bispectral index monitoring (BIS) detect the discrepancy of cerebral reperfusion during carotid endarterectomy? J Clin Anesth 21: 431-434.
18. Consales G, Chelazzi C, Rinaldi S, De Gaudio AR (2006) Bispectral Index compared to Ramsay score for sedation monitoring in intensive care units. Minerva Anestesiol 72: 329-336.

19. Yaman F, Ozcan N, Ozcan A (2012) Assessment of correlation between bispectral index and four common sedation scales used in mechanically ventilated patients in ICU. Eur Rev Med Pharmacol Sci 16: 660-666.

20. Gélinas C, Klein K, Naidech AM, Skrobik Y (2013) Pain, sedation, and delirium management in the neurocritically ill: Lessons learned from recent research. Semin Respir Crit Care Med 34: 236-243. 